\title{
Functional and expression analyses of two kinds of betaine aldehyde dehydrogenases in a glycinebetaine-hyperaccumulating graminaceous halophyte, Leymus chinensis
}

Shiro Mitsuya ${ }^{1 *}$, Asumi Tsuchiya ${ }^{1}$, Keiko Kono-Ozaki ${ }^{1}$, Takashi Fujiwara ${ }^{1}$, Teruhiro Takabe ${ }^{2}$ and Tetsuko Takabe ${ }^{2}$

\begin{abstract}
Glycinebetaine (GB) is an important compatible solute for salinity tolerance in many plants. In this study, we analyzed the enzymatic activity and the expression level of betaine aldehyde dehydrogenase (BADH), an important enzyme that catalyzes the last step in the GB synthesis in Leymus chinensis, a GB-hyperaccumulating graminaceous halophyte, and compared with those of barley, a graminaceous glycophyte. We have isolated cDNAs for two BADH genes, LCBADH1 and $L C B A D H 2$. LCBADH1 has a putative peroxisomal signal peptide (PTS1) at its C-terminus, while LCBADH2 does not have any typical signal peptide. Using immunofluorescent labeling, we showed that BADH proteins were localized to the cytosol and dot-shaped organelles in the mesophyll and bundle sheath cells of L.chinensis leaves. The affinity of recombinant $\mathrm{LCBADH} 2$ for betaine aldehyde was comparable to other plant BADHs, whereas recombinant $\mathrm{LCBADH} 1$ showed extremely low affinity for betaine aldehyde, indicating that LCBADH2 plays a major role in GB synthesis in L. chinensis. In addition, the recombinant LCBADH2 protein was tolerant to $\mathrm{NaCl}$ whereas LCBADH1 wasn't. The kinetics, subcellular and tissue localization of BADH proteins were comparable between L. chinensis and barley. The activity and expression level of BADH proteins were higher in L. chinensis compared with barley under both normal and salinized conditions, which may be related to the significant difference in the amount of GB accumulation between two plants.
\end{abstract}

Keywords: Barley; Betaine aldehyde dehydrogenase; Choline monooxygenase; Enzyme kinetics; Salinity stress; Subcellular localization

\section{Background}

Salinity is one of the biggest factors which limits the productivity of crops (Boyer 1982). In order to survive and continue growth, plants have developed many defense mechanisms which allow them to adapt to unsuitable environments. One of these mechanisms is the accumulation of compatible solutes. Compatible solutes differ among plant species and include sugar alcohols, amino acids and their derivatives, tertiary sulphonium compounds and quaternary ammonium compounds (Rhodes \& Hanson 1993; Bohnert \& Jensen 1996). Glycinebetaine (GB) is one of the most important compatible solutes. GB is present in bacteria, cyanobacteria, animals, and several plant families

\footnotetext{
* Correspondence: mitsuya@agr.nagoya-u.ac.jp

${ }^{1}$ Graduate School of Bioagricultural Sciences, Nagoya University, Chikusa, Nagoya 464-8601, Japan

Full list of author information is available at the end of the article
}

such as Graminaceae, Amaranthaceae, Asteraceae and Malvaceae (Rhodes \& Hanson 1993), and is known to efficiently stabilize the structure and function of proteins (Papageorgiou \& Murata 1995; Takabe et al. 1998) and to decrease the $T_{\mathrm{m}}$ of double-stranded DNA (Rees et al. 1993).

The biological effects of GB on plant stress tolerance have been shown using near-isogenic lines in maize and transgenic plants (Saneoka et al. 1995; Yang et al. 1995; Nomura et al. 1995, 1998; Sakamoto et al. 1998; Mohanty et al. 2002). In near-isogenic lines of maize differing in levels of GB accumulation, lines with abundant GB showed higher salt tolerance than GB-deficient lines (Saneoka et al. 1995; Yang et al. 1995). However, most crop plants such as rice accumulate little GB and are sensitive to salt stress. Therefore, to improve plant salt tolerance, it is important to elucidate the mechanism of $\mathrm{GB}$ 
biosynthesis to potentially introduce the ability of GB production into GB-nonaccumulators.

In plants, $G B$ is synthesized by the oxidation of choline via a two-step process: choline $\rightarrow$ betaine aldehyde $\rightarrow$ GB (Rathinasabapathi et al. 1997). The first and second steps are catalyzed by choline monooxygenase (CMO) and betaine aldehyde dehydrogenase (BADH), respectively (Arakawa et al. 1987; Brouquisse et al. 1989; Wood et al. 1996; Rathinasabapathi et al. 1997; Hibino et al. 2001; Nakamura et al. 2001; Mitsuya et al. 2011). Both steps occur in chloroplasts in Amaranthaceae (Weigel et al. 1988). On the other hand, in barley, GB is produced in a cooperative way in peroxisomes and cytosol catalyzed by NADPHdependent peroxisomal $\mathrm{CMO}(\mathrm{HvCMO})$ and cytosolic BADH (BBD2) (Fujiwara et al. 2008; Mitsuya et al. 2011), whereas it is not clear whether other graminaceous plants also have a non-chloroplastic pathway of GB production.

Leymus chinensis is a graminaceous and perennial grass that grows in the meadow steppes of Northeast China and Inner Mongolia, and is an important grass species for grazing (Kawanabe et al. 1994). L. chinensis consists of two ecotypes, a green type and a gray type, which differ in leaf color and ear shape Kawanabe et al. (1996). The gray type of $L$. chinensis is adaptable to saline, drought and alkaline conditions in comparison with the green type (Kawanabe et al. 1996) and can survive and still develop stolons in the presence of $500 \mathrm{mM} \mathrm{NaCl}$ (Ochiai and Matoh 2001). Moreover, L. chinensis can accumulate large amounts of GB ( $93 \mathrm{mM}$ ) which accounts for $30 \%$ of the total solute concentration in leaves grown in $200 \mathrm{mM}$ $\mathrm{NaCl}$ (Ochiai and Matoh 2001), indicating that L. chinensis is a GB-hyper-accumulating halophyte. However, the biosynthetic enzymes of GB and their regulation mechanism in L. chinensis have not been characterized thus far.

The objective of this study is to identify GB-biosynthetic BADH proteins in the graminaceous halophyte L. chinensis and to compare its characteristic with that of barley, a graminaceous glycophyte. For this purpose, we have isolated cDNAs for two kinds of $B A D H$ genes from $L$. chinensis, $L c B A D H 1$ and $L c B A D H 2$. Using the recombinant BADH proteins of $L$. chinensis, we have determined their activity and stability to $\mathrm{NaCl}$. The effect of salinity stress on the expression level of mRNA and protein of LcBADH was also investigated in L. chinensis plants. Also in this paper, we discuss the difference of the characteristic of BADH proteins between $L$. chinensis and barley, that may be related to the significant difference of the accumulation level of GB between two plants.

\section{Results}

\section{Cloning of $C D N A s$ for $\angle C B A D H 1$ and $\angle C B A D H 2$ genes in} L. chinensis

To isolate $B A D H$ cDNAs from $L$. chinensis, we constructed a cDNA library from leaves of salt-stressed $L$. chinensis and cloned $B A D H$ cDNAs by PCR using degenerate primers which were designed on the basis of the highly conserved amino acid sequences from several plants' BADH as described in Methods. Next, by screening of a cDNA library using the $B A D H$ fragment, eleven clones were isolated and sequenced. The nucleotide sequences of two of the clones, and that of nine clones were the same and named $L c B A D H 1$ and $L c B A D H 2$, respectively. The $L c B A D H 1$ and $L C B A D H 2$ cDNA contains an open reading frame of 1,521 bp and 1,509 bp encoding 506 and 502 amino acids, respectively (Figure 1). LcBADH1 has the putative peroxisomal signal peptide (Ser-Lys-Leu, underlined sequences in Figure 1) at its C-terminus (PTS1) (Baker and Sparkes 2005), while LcBADH2 does not have any typical signal peptide. Both $L c B A D H 1$ and $L c B A D H 2$ genes encode a conserved decapeptide (Val-Thr/Ser-Leu-GluLeu-Gly-Gly-Lys-Ser-xPro, xboxed sequences in Figure 1) which is highly conserved among general aldehyde dehydrogenases (Weretilnyk and Hanson 1990). LcBADH2 has cysteine at position 444 that is critical for high affinity to betaine aldehyde (Díaz-Sánchez et al. 2012) whereas LcBADH1 possesses a low betaine aldehyde affinity isoleucine at the corresponding position.

We performed a phylogenetic analysis using deduced polypeptide sequences of plant BADHs from six species of Graminaceae, five species of Amaranthaceae, two species of Fabaceae and Arabidopsis thaliana as a Brassicaceae. The result showed that plant BADHs were divided into two groups, monocotyledonous and dicotyledonous BADHs and that LcBADH1 and LcBADH2 were in the monocotyledonous BADH group (Figure 2). Furthermore the monocotyledonous BADH group was divided into two subgroups, which was consistent with the result of Arikit et al. (2011). The dicotyledonous BADH group was divided into amaranthaceous and fabaceous subgroups. LcBADH1 with the SKL motif was similar to peroxisomal barley BBD1 (93\% similarity) whereas LcBADH2 with no typical signal peptide was highly homologous with cytosolic barley BBD2 (96\% similarity) (Figure 2). Interestingly, most monocotyledonous BADHs, with the exception of LcBADH2 and BBD2, harbor an SKL motif at their C-terminus. Although it was reported that GB is synthesized in chloroplasts in plants (Chen and Murata 2011), graminaceous plants may have a different site for GB biosynthesis other than the chloroplasts.

\section{BADH activity of recombinant LCBADH1 and LCBADH2 proteins}

To determine the enzymatic characteristics of LcBADH1 and LcBADH2 proteins, both proteins were expressed in E. coli and purified by affinity chromatography. After enterokinase treatment for the removal of pET32a vectorderived tags, the eluates were separated by SDS-PAGE, which showed that both enzymes were purified to apparent 


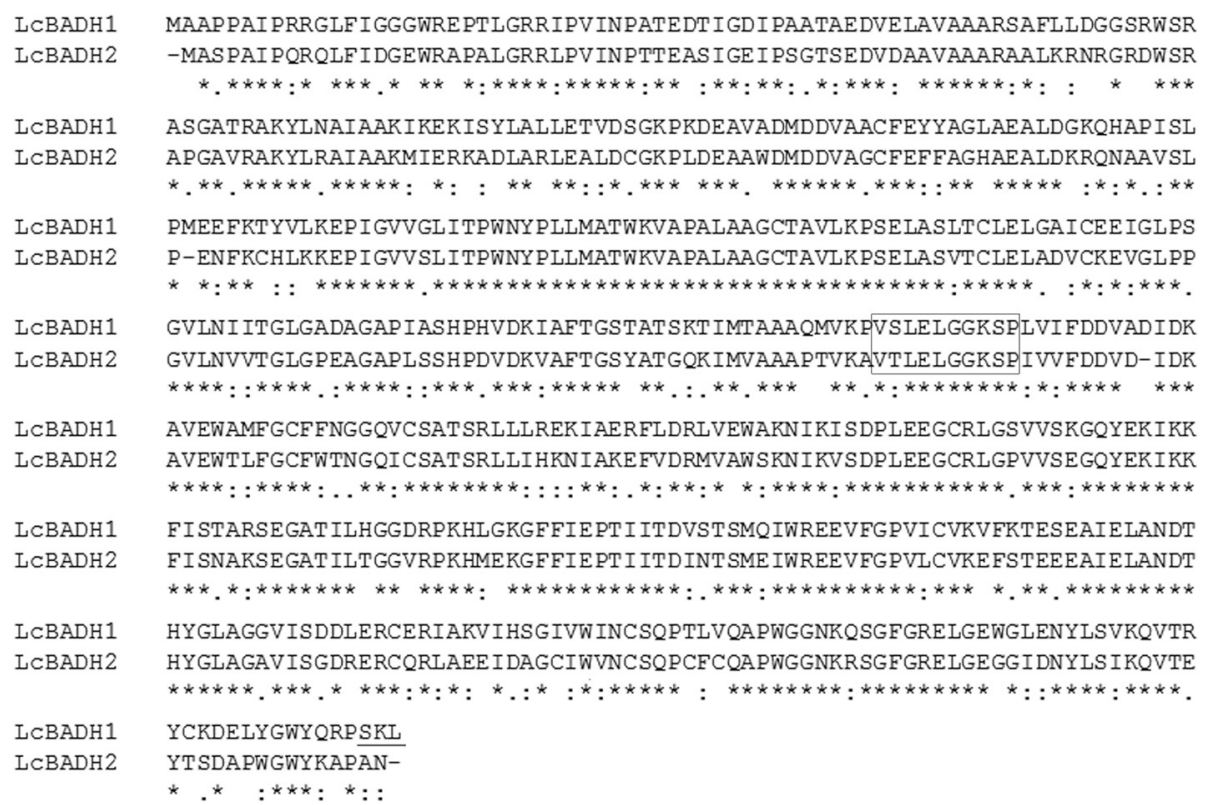

Figure 1 Comparison of the deduced amino acid sequences of the $\angle C B A D H 1$ and $L C B A D H 2$ genes. The deduced amino acid sequence of $\angle C B A D H 1$ (GenBank Accession No. AB711137) was aligned with that of $L C B A D H 2$ (BAD86758). The putative signal peptide for targeting to peroxisomes (SKL motif PTS1) is underlined. Ten amino acids boxed show a highly conserved region among aldehyde dehydrogenases. The symbols asterisk, colon and dot denote identical, conserved, and similar amino acids, respectively.

homogeneity (Additional file 1). The molecular mass of the purified proteins corresponded to that of the deduced amino acid sequences of LcBADH1 and LcBADH2 (approx $54 \mathrm{kDa})$.

Using these purified recombinant BADHs, we investigated the Michaelis constant $\left(K_{\mathrm{m}}\right.$ value) of LcBADH1 and LcBADH2 for betaine aldehyde (Additional file 2). The $K_{\mathrm{m}}$ values of LcBADH1 and LcBADH2 were $27300 \mu \mathrm{M}$ and $109 \mu \mathrm{M}$, respectively (Table 1). Because a high concentration of betaine aldehyde is toxic to plant cells (Rathinasabapathi et al. 1994), it is unlikely that LcBADH1 functions as a BADH in L. chinensis. In addition, the $V_{\max }$ value of LcBADH1 and LcBADH2 for betaine aldehyde was 1.59 and $1.26 \mathrm{U} \mathrm{mg}^{-1}$ protein, respectively. $V_{\max } / K_{\mathrm{m}}$, a criterion for catalytic activity, determined for betaine aldehyde of LcBADH1 was about 200-fold lower than that of LcBADH2. The kinetic characteristics of recombinant LcBADH1 and LcBADH2 proteins showed similar tendencies with that of the recombinant BBD1 and BBD2 proteins from barley, respectively (Table 2).

With regards to $\mathrm{NAD}^{+}$, the apparent $K_{\mathrm{m}}$ value of LcBADH1 and LcBADH2 was $15.6 \mu \mathrm{M}$ and $7.66 \mu \mathrm{M}$, respectively (Table 1 ). Also, when $\mathrm{NADP}^{+}$was used as an electron acceptor, the apparent $K_{\mathrm{m}}$ value of LcBADH2 was $3680 \mu \mathrm{M}$, which indicates that LcBADH2 prefers $\mathrm{NAD}^{+}$to $\mathrm{NADP}^{+}$as an electron acceptor (Table 1). However, LcBADH1 showed little BADH activity when $\mathrm{NADP}^{+}$ was used as an electron acceptor. $\boldsymbol{\omega}$-aminoaldehyde and $\mathrm{N}$-trimethylaminoaldehyde dehydrogenase activities of LCBADH1 and LCBADH2

As shown in Additional file 2, both LcBADH1 and LcBADH2 catalyzed the dehydrogenation of 4-aminobutyraldehyde (AB-ald), 3-aminopropionaldehyde (AP-ald), 4- $N$-trimethylaminobutyraldehyde (TMAB-ald) and 3-Ntrimethylaminopropionaldehyde (TMAP-ald). The $K_{\mathrm{m}}$ values of LcBADH1 for AB-ald, AP-ald, TMAB-ald and TMAP-ald were $48.1 \mu \mathrm{M}, 27.4 \mu \mathrm{M}, 56.5 \mu \mathrm{M}$ and $762 \mu \mathrm{M}$, respectively (Table 1 ). With regards to LcBADH2, $K_{\mathrm{m}}$ values for AB-ald, AP-ald, TMAB-ald and TMAP-ald were $1.96 \mu \mathrm{M}, 4.53 \mu \mathrm{M}, 22.1 \mu \mathrm{M}$ and $91.4 \mu \mathrm{M}$, respectively (Table 1). $V_{\max } / K_{\mathrm{m}}$ of LcBADH2 for AB-ald, AP-ald, TMAB-ald and TMAP-ald was higher than that of LcBADH1, indicating that LcBADH2 exhibited relatively high affinity for the $\omega$-aminoaldehyde and $N$-trimethylaminoaldehyde tested in this study compared with LcBADH1.

\section{Effect of $\mathrm{NaCl}$ treatment on the BADH activity of recombinant LCBADH1 and LCBADH2}

We examined the stability of recombinant LcBADH1 and LcBADH2 proteins in the presence of $\mathrm{NaCl}$. The recombinant barley BADH proteins, BBD1 and BBD2 (Fujiwara et al. 2008), were also used. After the recombinant proteins were incubated at the indicated concentrations of $\mathrm{NaCl}$ for $5 \mathrm{~min}$, the dehydrogenation activity of betaine aldehyde was measured by adding $5 \mathrm{mM}$ betaine aldehyde. The activity of LcBADH1 and BBD1 was significantly 


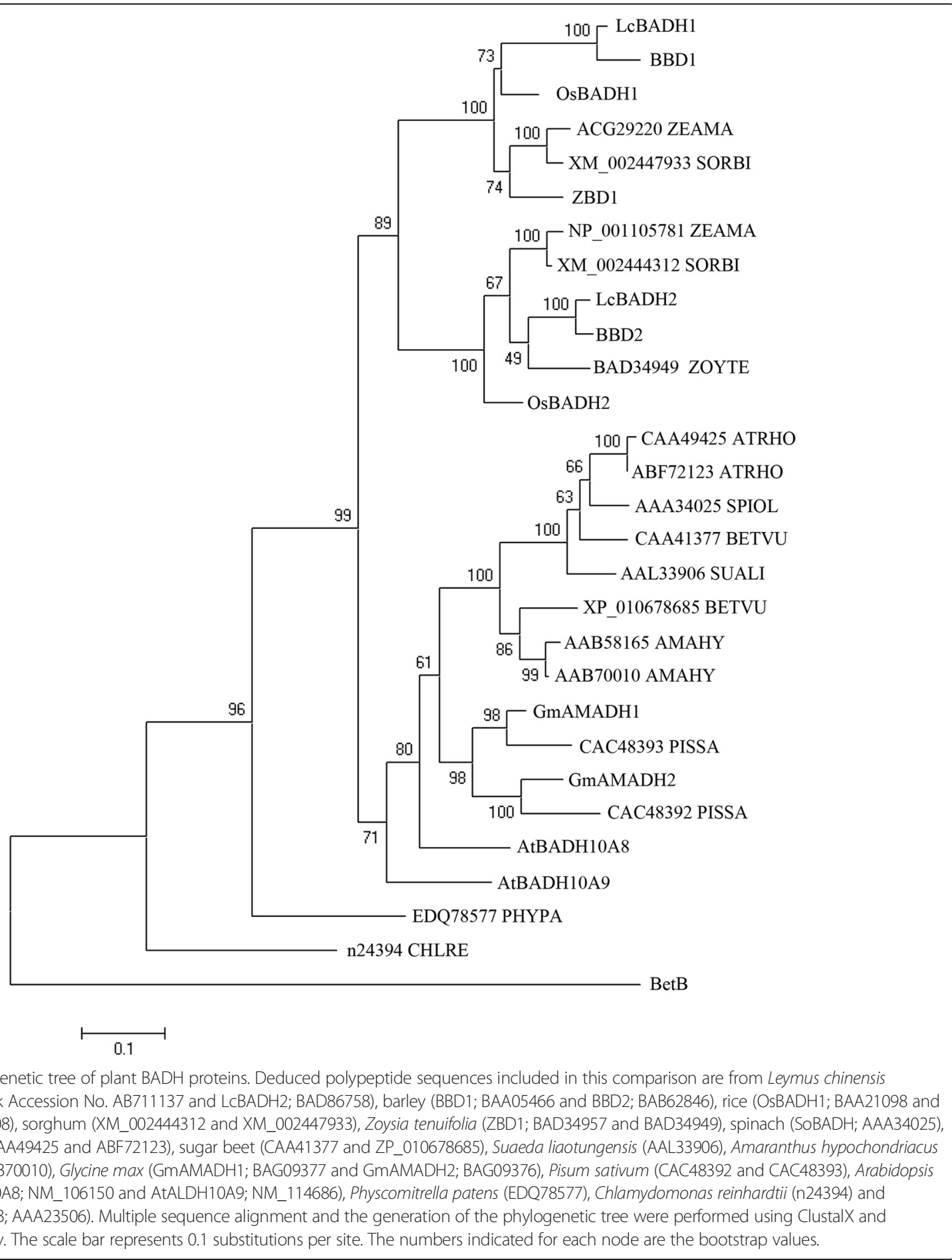

decreased by treatment with concentrations of $\mathrm{NaCl}$ greater than $50 \mathrm{mM}$ and $150 \mathrm{mM}$, respectively (Figure 3). On the other hand, the activity of LcBADH2 and BBD2 proteins decreased only at $\mathrm{NaCl}$ concentrations greater than $300 \mathrm{mM}$ (Figure 3 ). The activity of BBD2 protein decreased at concentrations of $\mathrm{NaCl}$ greater than $600 \mathrm{mM}$ and significantly in the presence of $1 \mathrm{M} \mathrm{NaCl}$. However,
LcBADH2 protein showed comparable activity with the control at concentrations of $\mathrm{NaCl}$ up to $1 \mathrm{M}$.

Tissue and subcellular localization of BADH and CMO-like proteins in $L$. chinensis leaves

Leaf blades of $L$. chinensis plants grown under normal conditions were used to determine the tissue and subcellular 
Table 1 Substrate specificity of recombinant LCBADH1 and LCBADH2 proteins

\begin{tabular}{|c|c|c|c|c|c|c|}
\hline \multirow[b]{2}{*}{ Substrates } & \multirow[b]{2}{*}{$K_{\mathrm{m}}(\mu \mathrm{M})$} & \multicolumn{3}{|l|}{ LcBADH1 } & \multicolumn{2}{|l|}{ LcBADH2 } \\
\hline & & $V_{\max }\left(\mathrm{U} \mathrm{mg}^{-1}\right.$ protein $)$ & $V_{\max } / K_{\mathrm{m}}$ & $K_{\mathrm{m}}(\mu \mathrm{M})$ & $V_{\max }\left(\mathrm{U} \mathrm{mg}^{-1}\right.$ protein $)$ & $V_{\max } / K_{\mathrm{m}}$ \\
\hline Betaine aldehyde & $27300 \pm 7000$ & $1.59 \pm 0.16$ & $5.96 \times 10^{-5} \pm 1.22 \times 10^{-5}$ & $109 \pm 10.0$ & $1.26 \pm 0.05$ & $1.16 \times 10^{-2} \pm 1.55 \times 10^{-4}$ \\
\hline AB-ald & $48.1 \pm 12.6$ & $1.29 \pm 0.08$ & $3.55 \times 10^{-2} \pm 1.28 \times 10^{-2}$ & $1.96 \pm 0.30$ & $1.01 \pm 0.04$ & $5.17 \times 10^{-1} \pm 3.27 \times 10^{-2}$ \\
\hline AP-ald & $27.4 \pm 6.30$ & $2.16 \pm 0.14$ & $1.03 \times 10^{-1} \pm 3.10 \times 10^{-2}$ & $4.53 \pm 0.81$ & $2.70 \pm 0.17$ & $5.96 \times 10^{-1} \pm 2.85 \times 10^{-2}$ \\
\hline TMAB-ald & $56.5 \pm 17.0$ & $1.33 \pm 0.19$ & $2.91 \times 10^{-2} \pm 5.69 \times 10^{-3}$ & $22.1 \pm 1.50$ & $1.10 \pm 0.02$ & $5.03 \times 10^{-2} \pm 4.18 \times 10^{-3}$ \\
\hline TMAP-ald & $762 \pm 175$ & $1.01 \pm 0.08$ & $1.22 \times 10^{-3} \pm 1.95 \times 10^{-4}$ & $91.4 \pm 9.60$ & $1.81 \pm 0.07$ & $2.00 \times 10^{-2} \pm 4.14 \times 10^{-4}$ \\
\hline $\mathrm{NAD}^{+}$ & $15.6 \pm 5.70$ & $1.36 \pm 0.12$ & $1.11 \times 10^{-1} \pm 3.69 \times 10^{-2}$ & $7.66 \pm 0.60$ & $0.683 \pm 0.01$ & $9.02 \times 10^{-2} \pm 9.34 \times 10^{-3}$ \\
\hline $\mathrm{NADP}^{+}$ & & N.D. & & $3680 \pm 725$ & $0.273 \pm 0.02$ & $7.60 \times 10^{-5} \pm 8.29 \times 10^{-6}$ \\
\hline
\end{tabular}

For kinetic analyses of the substrates, reaction mixtures contained $50 \mathrm{mM} \mathrm{HEPES}-\mathrm{KOH}$ (pH 8.0), $500 \mu \mathrm{M}$ NAD ${ }^{+}$and various concentrations of each substrates. For kinetic analyses of $\mathrm{NAD}^{+}$and $\mathrm{NADP}^{+}$, reaction mixtures contained $50 \mathrm{mM} \mathrm{HEPES}-\mathrm{KOH}(\mathrm{pH} 8.0)$, betaine aldehyde $(5 \mathrm{mM}$ for LCBADH1; $200 \mu \mathrm{M}$ for LcBADH2) and the various concentrations of $\mathrm{NAD}^{+}$or $\mathrm{NADP}^{+}$. Enzyme activities were determined as described in Materials and Methods. Values represent the mean of three experiments $\pm \mathrm{SE}$. AB-ald, 4-aminobutyraldehyde; AP-ald, 3-aminopropionaldehyde; TMAB-ald, 4-N-trimethylaminobutyraldehyde; TMAP-ald, 3-N-trimethylaminopropionaldehyde. N.D.; not detected.

localization of BADH proteins. The strong green fluorescent signals for BADH were detected in the cytosol and dot-shaped organelles in mesophyll and bundle sheath cells, which did not overlap with the autofluorescence of chloroplasts (shown as magenta) (Figure 4a).

We also examined the localization of CMO-like proteins in the leaves using the anti-HvCMO peptide antibody (Mitsuya et al. 2011). The fluorescent signals for CMOlike proteins were detected in the non-chloroplastic dotshaped organelles in mesophyll and bundle sheath cells (Figure 4b), which is similar to barley where CMO is localized in peroxisomes in mesophyll and bundle sheath cells (Mitsuya et al. 2011).

We also used the leaf blades grown under saline conditions but the localization of $\mathrm{BADH}$ and $\mathrm{CMO}$ proteins was comparable to those under normal conditions (data not shown).

Effect of $\mathrm{NaCl}$ on the accumulation of $\mathrm{GB}$, choline and GB-biosynthetic proteins in L. chinensis and barley

The concentration of GB in the sixth leaf blades and roots of $L$. chinensis and barley under normal and saline conditions were measured. Because L. chinensis grows slower than barley, L. chinensis and barley plants were hydroponically grown for four and three weeks respectively, to obtain plants with the same leaf stage (the youngest fully- expanded leaf was sixth from the bottom). Four-week-old L. chinensis and three-week-old barley plants were then treated with $300 \mathrm{mM} \mathrm{NaCl}$ for $72 \mathrm{~h}$. The concentration of GB increased significantly in the presence of $\mathrm{NaCl}$ in the sixth leaf blades and roots of both plants and was higher in the leaves than in the roots (Figure 5a). L. chinensis accumulated much more GB than barley under both normal and saline conditions (Figure 5a).

The concentration of choline, a precursor of GB, was also measured using sixth leaf blades of L. chinensis and barley plants. Barley showed higher concentrations of choline than L. chinensis, although the concentration was not significantly affected by $\mathrm{NaCl}$ treatment in both plants (Figure 5b).

The level of transcripts of $L c B A D H 1$ and $L c B A D H 2$ genes in the sixth leaf blades of $L$. chinensis was examined using real-time PCR. The levels of $L c B A D H 1$ and $L c B A D H 2$ mRNAs increased in the presence of $300 \mathrm{mM} \mathrm{NaCl}$ and showed peak accumulation at $24 \mathrm{~h}$ (Figure 6a). The CMOlike mRNA level under saline conditions, determined using the EST information (Genbank accession number EU003877), was comparable with that under control conditions up to $48 \mathrm{~h}$, but had increased at $72 \mathrm{~h}$ (Figure 6a).

We also determined the protein level of BADH and CMO-like in the sixth leaf blades and roots of $L$. chinensis and barley plants treated with 0 and $300 \mathrm{mM} \mathrm{NaCl}$ for

Table 2 Comparison of the specificity of Leymus chinensis and barley BADH proteins against betaine aldehyde

\begin{tabular}{lllll}
\hline Protein & $\boldsymbol{K}_{\mathbf{m}}(\boldsymbol{\mu M})$ & $\boldsymbol{V}_{\max }\left(\mathbf{U} \mathbf{~ m g}^{-1}\right.$ protein) & $\boldsymbol{V}_{\max } / \boldsymbol{K}_{\mathbf{m}}$ & Reference \\
\hline LCBADH1 & $27300 \pm 7000$ & $1.59 \pm 0.16$ & $5.96 \times 10^{-5} \pm 1.22 \times 10^{-5}$ & \\
& & & & This study \\
LCBADH2 & $109 \pm 10.0$ & $1.26 \pm 0.05$ & $1.16 \times 10^{-2} \pm 1.55 \times 10^{-4}$ & Fujiwara et al. (2008) \\
BBD1 & $19900 \pm 3900$ & $1.07 \pm 0.10$ & $5.37 \times 10^{-5}$ & $1.08 \times 10^{-1}$ \\
BBD2 & $18.9 \pm 1.40$ & $2.05 \pm 0.06$ & & \\
\hline
\end{tabular}

Kinetic analyses were performed as described in Table 1. Values represent the mean of three experiments \pm SE. The values for Barley BBD1 and BBD2 were cited from Fujiwara et al. (2008). 


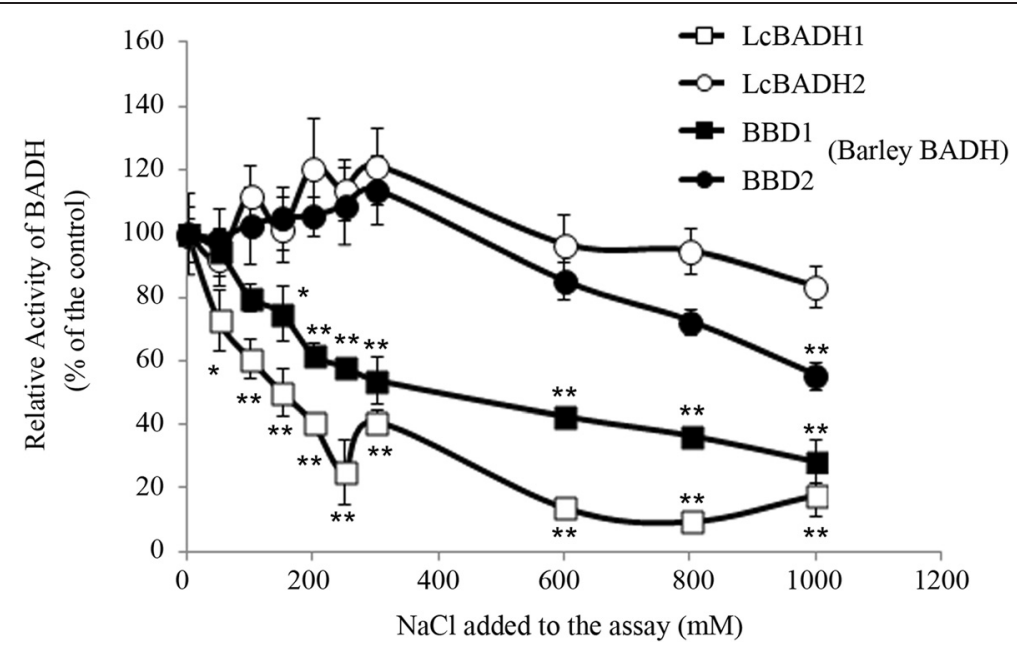

Figure 3 Effect of the application of $\mathrm{NaCl}$ on the activity of BADH proteins from Leymus chinensis and barley. Open squares and circles represent the recombinant protein of $\mathrm{LCBADH} 1$ and $\mathrm{LCBADH}$ 2, respectively. The recombinant barley BADH proteins, BBD1 (closed square) and BBD2 (closed circle), were also used for the assay. The recombinant protein was incubated in the standard mixture supplemented with the indicated concentrations of $\mathrm{NaCl}$ for $5 \mathrm{~min}$ and used for the spectrophotometrical measurement of BADH activity as described in Materials and methods. Data represent the mean of three experiments $\pm S E(n=3)$. Vertical bars represent $S E$. The symbols ${ }^{*}$ and ${ }^{*}$ represent significant differences from control values in each protein at $P<0.05$ and $P<0.01$, respectively (Dunnett's test).

$72 \mathrm{~h}$. The protein level of BADH and CMO-like was greater in the leaves of both plants than in the roots (Figure 6b). The amount of BADH and CMO-like proteins was greater in L. chinensis than in barley under normal conditions. On the other hand, the expression level of BADH protein was increased in barley but not in $L$. chinensis in the presence of $\mathrm{NaCl}$. We also determined BADH activity using crude protein extracted from the sixth leaf blades of $L$. chinensis plants. The BADH activity in $L$. chinensis leaves under normal and saline conditions was 0.51 and $0.54 \mathrm{nmol} \mathrm{min}{ }^{-1} \mathrm{mg}^{-1}$ protein, respectively, which was much higher than the activity in barley leaves

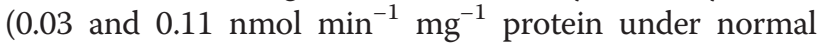
and saline conditions, respectively) (Ishitani et al. 1993) (Table 3).

\section{Discussion}

\section{The GB-biosynthetic BADH protein in L. chinensis}

We have isolated cDNAs for two kinds of $B A D H$ genes, $L c B A D H 1$ and $L c B A D H 2$ from $L$. chinensis and have shown that LCBADH1 and LcBADH2 proteins were putatively localized to peroxisome-like dot-shaped organelles and cytosol, respectively, in mesophyll and bundle sheath cells in the leaves (Figure 4). It is suggested that cytosolic LcBADH2 showing high affinity to betaine aldehyde (true BADH; Fitzgerald et al. 2009) plays a major role in GB biosynthesis in $L$. chinensis whereas LcBADH1 shows much low affinity to betaine aldehyde (highly BADH homology aminoaldehyde dehydrogenase; Fitzgerald et al. 2009). The result was consistent with other graminaceous plants such as barley and rice that have a true BADH
(BBD2 in barley and OsBADH2 in rice) and a highly BADH homology aminoaldehyde dehydrogenase (BBD1 in barley and OsBADH1 in rice) (Fujiwara et al. 2008; Mitsuya et al. 2009). Díaz-Sánchez et al. (2012) has reported that, in spinach BADH, small amino acid residues such as alanine or cysteine at position 441 is critical for the high affinity to betaine aldehyde whereas isozymes possessing isoleucine at the position show low affinity to betaine aldehyde. LcBADH2 and BBD2 with high affinity to betaine aldehyde also possess cysteine and LcBADH1, BBD1, and OsBADH1 with low affinity to betaine aldehyde possess isoleucine at the corresponding position, which corresponds to the result of Díaz-Sánchez et al. (2012), however OsBADH2 has a isoleucine at this position but showed moderately high affinity to betaine aldehyde (Mitsuya et al. 2009).

Together with the result of subcelullar localization of CMO-like protein (Figure 4), it is indicated that L. chinensis produces GB by oxidizing choline in a co-operative way via dot-shaped organelles and cytosol in mesophyll and bundle sheath cells in the leaves. It is similar to GB production that is performed in two separated subcellular compartments (peroxisomes and cytosol) in barley (Mitsuya et al. 2011, Mitsuya et al. 2013). This result supports that graminaceous plants have a non-chloroplastic pathway of GB production unlike Amaranthaceae (Weigel et al. 1988).

\section{The comparison of the characteristics of BADH proteins} between $L$. chinensis and barley

Next, we compared the characteristics of the GBbiosynthetic BADH proteins between $L$. chinensis and 


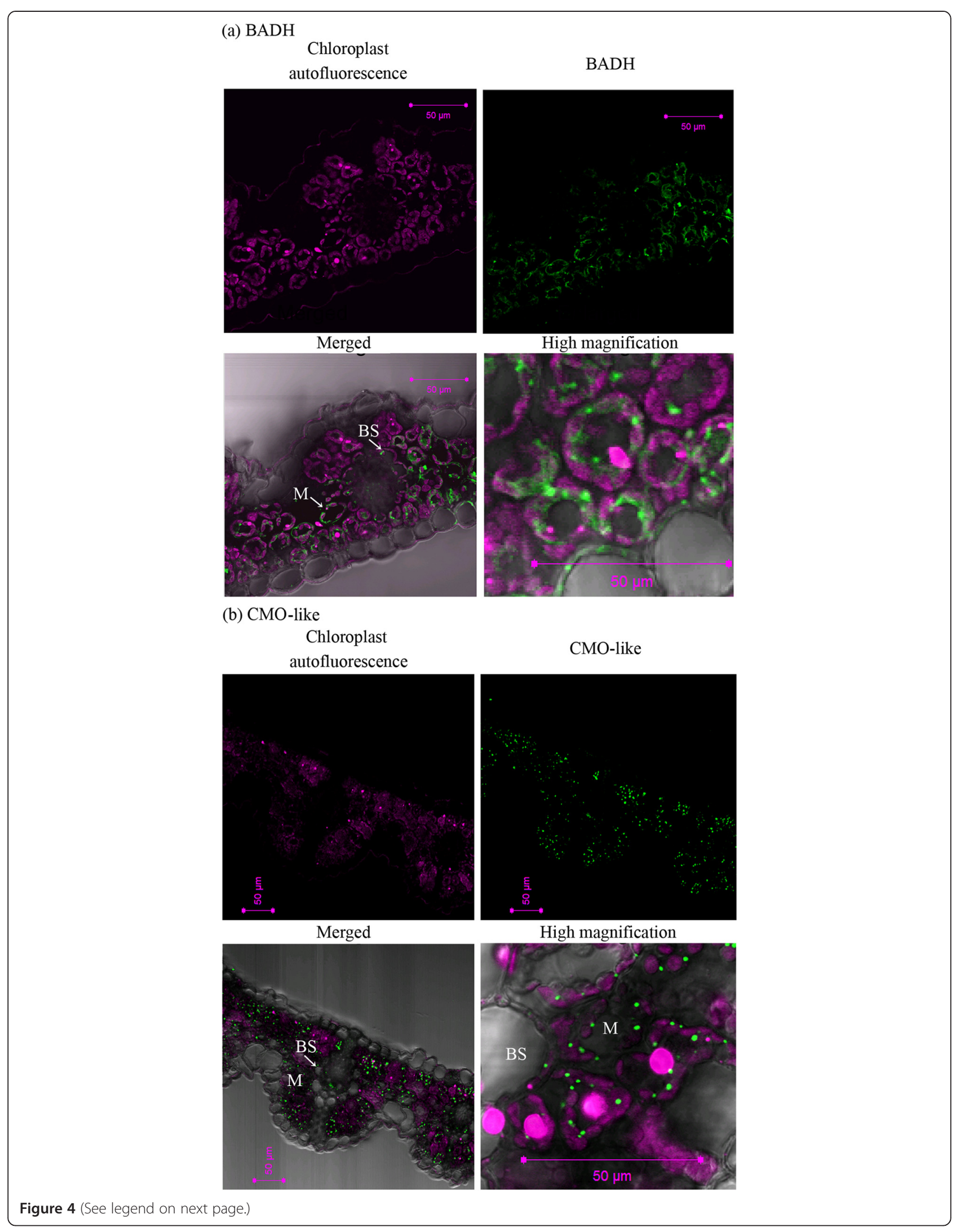


(See figure on previous page.)

Figure 4 Subcellular localization of (a) BADH and (b) CMO-like proteins in the leaf blades of Leymus chinensis plants. The middle part of leaf blades of the youngest fully-expanded leaf of four-week-old L. chinensis plants was used. The magenta autofluorescence emitted by chloroplasts, the green fluorescence of BADH and CMO-like proteins detected with fluorescein-conjugated goat anti-rabbit antibody, merged image and enlarged image are shown. Scale bars represent $50 \mu \mathrm{m}$. $M$ mesophyll, BS bundle sheath.

barley showing different levels of GB accumulation (Figure 5a). The catalytic efficiency of BADH and its subcellular and tissue localization were comparable between L. chinensis and barley (Table 2 and Figure 4), which indicates that those characteristics were not correlated with the significant difference of GB accumulation between two graminaceous plants. In addition, the concentration of choline, a precursor of GB, was rather higher in barley than in L. chinensis (Figure 5b). On the other hand, the expression analysis of BADH and CMO proteins indicates that much larger $\mathrm{GB}$ accumulation in L. chinensis in comparison to barley can be correlated with constant higher expression level of $\mathrm{BADH}$ (and CMOlike) proteins under normal conditions in L. chinensis (Table 3, Figure 6). Because GB is a stable end product of metabolism (Grattan and Grieve 1985), it is indicated that constitutive production of GB at high levels under normal conditions during the growth causes high accumulation of GB in L. chinensis.

\section{The mechanism of salinity-induced increase of GB production in $L$. chinensis}

The accumulation of GB was enhanced by salinity in $L$. chinensis (Figure 5a), but the expression level of BADH and $\mathrm{CMO}$-like proteins did not increase in the presence of $\mathrm{NaCl}$ (Figure 6). Also, the size of the free choline pool in the leaves of $L$. chinensis was comparable between normal and salinized conditions (Figure 5b). At the moment, it is difficult to conclude how salinity induced the increased production of GB in L. chinensis. So far, it was reported that the increase of GB accumulation in the presence of $\mathrm{NaCl}$ is caused by the increased expression and activity of BADH or choline oxidizing protein in graminaceous plants (Ishitani et al. 1993, Nakamura et al. 2001, $\mathrm{Su}$ et al. 2006). From the data in this study, it is indicated that the expression of $\mathrm{BADH}$ protein is not a limiting factor for GB synthesis under salinity in L. chinensis. It is possible to suggest that the metabolic flux to choline from its precursors [ethanolamine and successively-methylated ethanolamine derivatives catalyzed by phosphoethanolamine $N$-methyltransferase (PEAMT)] may be increased and the increased choline is immediately converted to betaine aldehyde and $\mathrm{GB}$ in salinized L. chinensis. In transgenic tobacco expressing spinach $\mathrm{CMO}$, the supply of endogenous choline or its precursors mono-and dimethylethanolamine is one of the limiting factors of GB biosynthesis (Nuccio et al. 1998). Moreover, the overexpression of PEAMT enhances the production of choline and GB in tobacco (McNeil et al. 2000). The regulation of PEAMT could be the next target to determine the mechanism of how GB production was increased by salinity in L. chinensis.

Since GB is produced in a co-operative way in the cytosol and dot-shaped organelles in L. chinensis (Figure 4), it is also necessary to determine whether the increase of GB under salinity is attributed by the increased activity of the transport of choline and/or betaine aldehyde in L. chinensis. It was previously shown that, in tobacco plants that express spinach $\mathrm{CMO}$ in the chloroplasts, the import of choline into the chloroplasts is a major constraint on GB synthesis (McNeil et al. 2000).

\section{Effect of $\mathrm{NaCl}$ treatment on the BADH activity of recombinant LCBADH1 and LCBADH2}

Interestingly, recombinant proteins of $\mathrm{LcBADH} 2$ and barley BBD2 showed no reduction of its activity under the treatment of $\mathrm{NaCl}$ up to $300 \mathrm{mM}$ (Figure 3). This result indicates that those proteins can function in the presence of reasonable concentrations of $\mathrm{NaCl}$ in the intracellular space. In contrast, it was reported that the recombinant $\mathrm{BADH}$ proteins from spinach, salttolerant mangrove Avicennia marina and E. coli showed 30 to $60 \%$ inhibition in the presence of $300 \mathrm{mM} \mathrm{NaCl}$ in vitro (Hibino et al. 2001; Oishi and Ebina 2005). These indicate that LcBADH2 and BBD2 are more tolerant to $\mathrm{NaCl}$ in comparison to other plants' BADH. By identifying the protein domains that allow LcBADH2 and BBD2 to maintain the activity under high concentrations of $\mathrm{NaCl}$, it could be possible to improve the salt tolerance of other plants' BADH.

\section{Other possible functions of LCBADH1 and LCBADH2 proteins}

As well as the dehydrogenation of betaine aldehyde, LcBADH1 and LcBADH2 catalyzed the dehydrogenation of $\omega$-aminoaldehyde (AB-ald and AP-ald) and $N$-trimethylaminoaldehyde (TMAB-ald and TMAP-ald) (Table 1). It was reported that not only BADHs from barley, rice, spinach and Zoysia tenuifolia, but also human and E. coli BADHs oxidize AB-ald and AP-ald (Chern and Pietruszko 1995; Trossat et al. 1998; Incharoensakdi et al. 2000; Livingstone et al. 2003; Oishi and Ebina 2005; Bradbury et al. 2008; Fujiwara et al. 2008). The affinity to aminoaldehydes was not so different between LcBADH1 and LcBADH2 or among LcBADHs and other plants' BADHs unlike that to betaine aldehyde. In addition, LcBADH1 

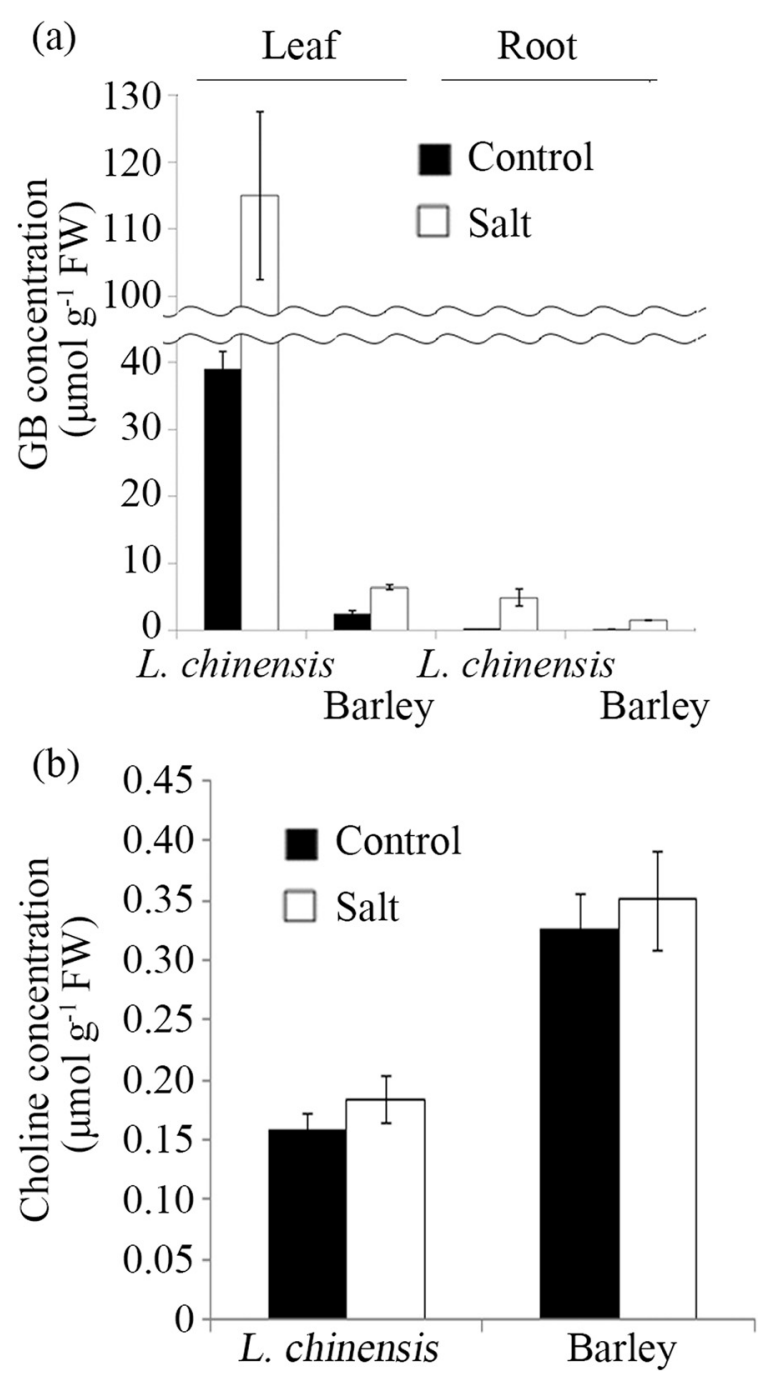

Figure 5 Effect of the application of $\mathrm{NaCl}$ on the accumulation of $\mathrm{GB}$ and choline in Leymus chinensis and barley plants. Four-week-old L. chinensis and three-week-old barley plants grown hydroponically with same leaf stage (the youngest fully-expanded leaf was sixth from the bottom) were treated with 0 and $300 \mathrm{mM} \mathrm{NaCl}$ for $72 \mathrm{~h}$. The sixth leaf blades and roots were harvested and used for the analyses. (a) The concentration of GB in the sixth leaf blades and roots. (b) The concentration of choline in the sixth leaf blades. Data are means $\pm S E(n=3)$. Vertical bars represent SE.

and LcBADH2 showed higher affinity to aminoaldehydes in comparison to that of betaine aldehyde, which is consistent with other plants' BADH (Livingstone et al. 2003; Oishi and Ebina 2005; Fujiwara et al. 2008; Mitsuya et al. 2009). AB-ald and AP-ald are known as intermediates in polyamine degradation in plants, although physiological functions of AB-ald and AP-ald are still unclear (Awal et al. 1995; Binda et al. 1998). It was reported that rice $\mathrm{BADH}$ protein (OsBADH2) has a role in the dehydrogenation of AB-ald to produce $\gamma$-aminobutyric acid (GABA) (Chen et al. 2008). GABA is also accumulated in response to various abiotic stresses such as salinity (Kinnersley and Turano 2000). Moreover, impaired GABA transaminase which functions in GABA catabolism, causes salt hypersensitivity in Arabidopsis plants (Renault et al. 2010). Therefore, LcBADH1 and LcBADH2 may possibly contribute to salt tolerance via the biosynthesis of GABA as well as GB in L. chinensis.

TMAB-ald and TMAP-ald are derived from AB-ald and AP-ald by the trimethylation of primary amino group and also catalyzed by barley BBD1 and BBD2 (Fujiwara et al. 2008). TMAB-ald is the intermediate of carnitine synthesis in mammals and some microorganisms (Vaz and Wanders 2002; Hassan et al. 2007). Since information on the physiological function of TMAP-ald in plants is unavailable, further study is needed to elucidate the physiological role of LcBADH proteins in $L$. chinensis plants. 


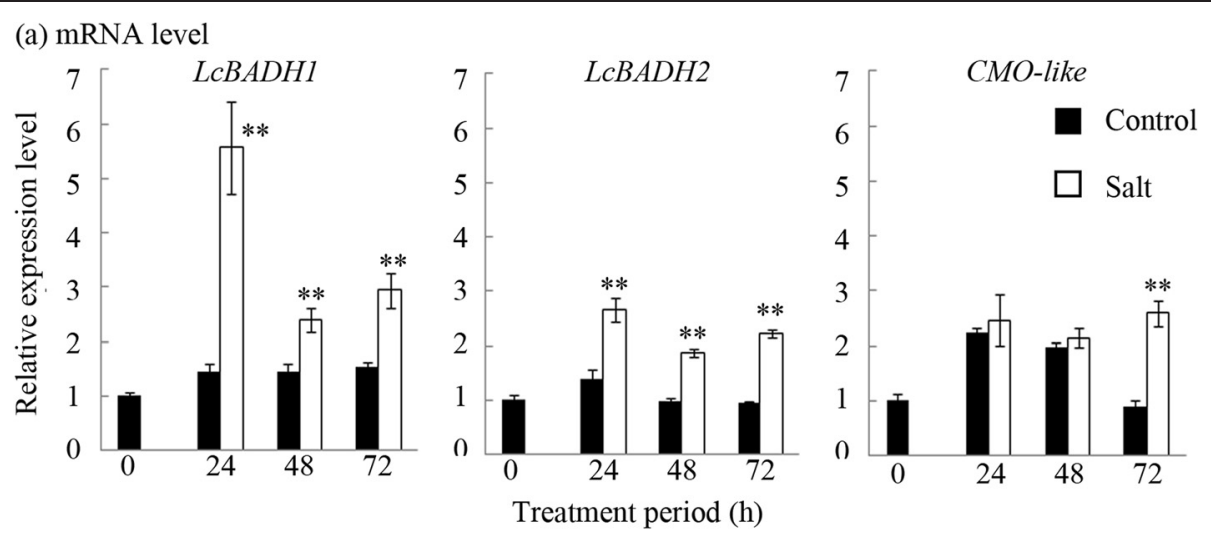

(b) Protein level

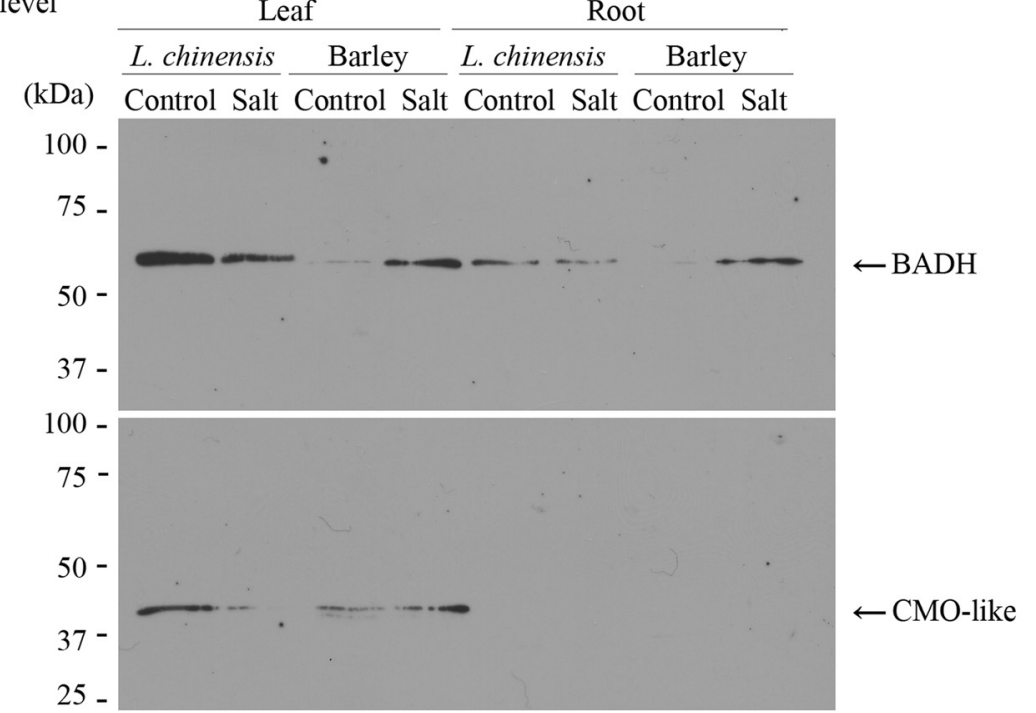

Figure 6 Expression pattern of mRNA and proteins of BADH and CMO-like in Leymus chinensis and barley plants under normal and saline conditions. Four-week-old $L$. chinensis and three-week-old barley plants grown hydroponically with same leaf stage (the youngest fully-expanded leaf was sixth from the bottom) were treated with 0 and $300 \mathrm{mM} \mathrm{NaCl}$ for $72 \mathrm{~h}$. The sixth leaf blades and roots were harvested and used for the analyses. (a) Realtime PCR analysis of the transcript level of $L C B A D H 1, \angle C B A D H 2$ and $C M O$-like genes under normal and saline conditions in the sixth leaf blades. $L C T$ Tubulin was used as an internal control to normalize for variation in the amount of cDNA template. Data show the mean of relative values with one unit being control $(0 \mathrm{~h}) \pm \mathrm{SD}$ of three biological replicates. The symbols ** represent significant differences from control values at each treatment period at $\mathrm{P}<0.01$ (Student's t-test). (b) Protein gel-blot analyses of BADH and CMO-like proteins. The lanes were loaded with protein extracted from sixth leaf blades and roots equivalent to $0.25 \mathrm{mg}$ FW. The sizes of molecular mass standards are shown on the left in $\mathrm{kDa}$.

Table 3 BADH activity in the leaves of Leymus chinensis and barley plants grown under normal and salinized conditions

\begin{tabular}{llll}
\hline Species & Treatment & $\begin{array}{l}\text { BADH activity } \\
\text { (nmol } \mathbf{~ i n}^{-1} \mathbf{~ m g}^{-1} \text { protein) }\end{array}$ & Reference \\
\hline L. chinensis & Control & $0.51 \pm 0.023$ & This study \\
& $\mathrm{NaCl}$ & $0.54 \pm 0.048$ & \\
Barley & $\mathrm{Control}$ & 0.03 & $\begin{array}{l}\text { Ishitani et al. } \\
\end{array}$ \\
& $\mathrm{NaCl}$ & 0.11 & $(1993)$ \\
\hline
\end{tabular}

\section{Conclusions}

We have isolated cDNAs for $L c B A D H 1$ and $L c B A D H 2$ xgenes which encode two kinds of BADH protein in $L$. chinensis plants, a GB-hyperaccumulating graminaceous halophyte. The analysis of enzyme kinetics indicated that cytosolic LcBADH2 protein plays a major role in $\mathrm{GB}$ biosynthesis. In addition, the recombinant LcBAEDH2 protein was tolerant to $\mathrm{NaCl}$ whereas LcBADH1 wasn't. It is indicated that $L$. chinensis produces GB by oxidizing choline in a co-operative way via dot-shaped organelles and cytosol in mesophyll and bundle sheath cells in the leaves. The kinetics, subcellular and tissue localization of $\mathrm{BADH}$ proteins were comparable between $L$. chinensis and barley, a Graminaceae accumulating less amounts of 
GB. The activity and expression level of BADH proteins were higher in L. chinensis compared with barley under both normal and salinized conditions, which may be related to the significant difference in the amount of GB accumulation between two plants.

\section{Methods}

Plant materials and growth conditions

Leymus chinensis (Trin.) Tzvel. plants consist of two ecotypes, and, the gray type of L. chinensis was grown in soil in a greenhouse of Nagoya University (Nagoya, Japan, $35^{\circ}$ $\left.9^{\prime} \mathrm{N}, 136^{\circ} 58^{\prime} \mathrm{E}\right)$. The illumination and temperature were not controlled. The plant is perennial and developed stolons and shoots from the nodes during April to October. Therefore, the experiments using plants were conducted during this period of the year.

For $\mathrm{NaCl}$ stress treatment, the developed stolons containing some nodes were cut, put into vermiculite and grown hydroponically in the culture solution $[2.5 \mathrm{mM}$ $\mathrm{KH}_{2} \mathrm{PO}_{4}, 1 \mathrm{mM} \mathrm{MgSO}$, $5 \mathrm{mM} \mathrm{KNO}, 1 \mathrm{mM} \mathrm{Ca}\left(\mathrm{NO}_{3}\right)_{2}$, $0.1 \mathrm{mM}$ Fe-EDTA, $70 \mu \mathrm{M} \mathrm{H}_{3} \mathrm{BO}_{3}, 1 \mu \mathrm{M} \mathrm{MnCl}, 0.5 \mu \mathrm{M}$ $\mathrm{CuSO}_{4}, 1.54 \mu \mathrm{M}\left(\mathrm{NH}_{4}\right)_{6} \mathrm{Mo}_{7} \mathrm{O}_{24}, \mathrm{pH}$ 5.5], where axillary buds were grown into plantlets. Plants were grown in a growth chamber with $13 \mathrm{~h}$ of illumination (about $200 \mu \mathrm{mol} \mathrm{m}{ }^{-2} \mathrm{~s}^{-1}$ at plant level, $25^{\circ} \mathrm{C}$ ) and $11 \mathrm{~h}$ of darkness at $20^{\circ} \mathrm{C}$. After the emergence, the plantlets were grown for four weeks, and treated with salinity stress. For $\mathrm{NaCl}$ treatment, 4-week-old plants were treated with the nutrient solution containing $300 \mathrm{mM} \mathrm{NaCl}$ and grown for further $72 \mathrm{~h}$. Salinity treatment was initiated one hour after the start of the light period.

We have also used barley (Hordeum vulgare L. cv. Haruna-nijyo) for the comparison with L. chinensis. Seeds of barley were surface sterilized and grown hydroponically as described previously (Fujiwara et al. 2010). Three-week-old seedlings were treated with the nutrient solution containing $300 \mathrm{mM} \mathrm{NaCl}$ and grown for further $72 \mathrm{~h}$.

After treatment, plants were collected at the indicated period and used for further experiments. After treatment, plants were collected at the indicated period, immediately frozen with liquid $\mathrm{N}_{2}$ and preserved at $-80^{\circ} \mathrm{C}$ until use. For immunofluorescent labeling experiments, fresh plant samples were used for excising the segments and fixiation using a fixation buffer, according to Mitsuya et al. (2011).

\section{Cloning of $\angle C B A D H$ CDNAs and construction of expression vectors}

The fragment of $L c B A D H$ cDNA was amplified by PCR from $\mathrm{CDNA}$ of the leaves of $L$. chinensis using degenerate primers (BADHF and BADHR; Additional file 3) designed on the basis of the highly conserved amino acid sequences from several plant BADH cDNAs of Atriplex hortensis (Xiao et al. 1995), sugar beet (McCue and Hanson 1992), spinach (Weretilnyk and Hanson 1990), barley (Ishitani et al. 1995) and rice (Nakamura et al. 1997). A cDNA library of the leaves of salt-treated $L$. chinensis plants was constructed as described previously (Inada et al. 2005). A partial cDNA fragment of the $L c B A D H$ gene which was obtained by the above PCR was used as a probe to screen the cDNA library. The ${ }^{32} \mathrm{P}$-labeled probe was prepared using the Megaprime DNA labeling system (Amersham Bioscience, Uppsala, Sweden). After library screening, the positive candidates were excised with pBluescript SK(-) vector, and sequenced as described previously (Inada et al. 2005). Because the 5 -terminus of the open reading frame (ORF) of $L c B A D H 1$ gene was not included in the clone, the cDNA sequence containing the entire coding region was obtained by 5'-RACE. THe 5'-RACE-PCR was performed with the isolated total RNAs of L. chinensis by a SMART RACE cDNA amplification kit (Clontech, Palo Alto, CA, USA). Sequence data from this article has been deposited at DDBJ/EMBL/GenBank under accession number AB711137 (for $L c B A D H 1$ ) and AB183716 (for LcBADH2). The primers used in this study are listed in Additional file 3.

\section{Sequence alignment and construction of a phylogenetic tree}

The deduced amino acid sequences of $L c B A D H 1$ and $L c B A D H 2$ were aligned by the N-J method using ClustalX software (Larkin et al. 2007). The phylogenetic tree was built using the MEGA6 program (Tamura et al. 2013). The tree was inferred by using the maximum likelihood method with 1000 bootstrap replicates. The initial tree for the heuristic search was obtained automatically by applying Neibor-Join and BioNJ algorithms to a matrix of pairwise distances estimated using a JTT model, and then selecting the topology with a superior log likelihood value. The tree was drawn to scale, with branch lengths measured in the number of substitutions per site. All positions with less than $50 \%$ site coverage were eliminated.

\section{Purification of recombinant BADH proteins}

The ORF of $L c B A D H 1$ and $L c B A D H 2$ was amplified by PCR using the primer set of LcB1sen3 and LcB1ant3, LcB2sen3 and LcB2ant3, respectively (Additional file 3). They were cloned into pET32a vector (Novagen, Madison, WI). Recombinant LcBADH1 and LcBADH2 proteins were obtained as described previously (Fujiwara et al. 2008). The recombinant LcBADH1 and LcBADH2 proteins were subjected to SDS-PAGE to confirm their homogeneous purification. Recombinant barley BBD1 and BBD2 proteins were also obtained as described previously (Fujiwara et al. 2008). Protein concentration was determined using the Bio-Rad 
Bradford Protein Assay (Bio-Rad, Hercules, CA, USA) using BSA as a standard.

\section{Enzyme assays}

Betaine aldehyde chloride was obtained from SigmaAldrich (St Louis, MO). The diethylacetals of AB-ald and AP-ald were obtained from Sigma-Aldrich and Tokyo Kasei Kogyo (Tokyo), respectively. TMAB-ald and TMAP-ald were distributed by Professor Nobuhiro Mori (Tottori University, Japan). They were hydrolyzed as described previously (Fujiwara et al. 2008) and neutralized by adding equivalent volume of $\mathrm{KOH}$. Aldehyde dehydrogenase activities were determined as described previously (Fujiwara et al. 2008). One unit of enzyme activity is defined as the amount of enzyme that catalyzes the formation of $1 \mu \mathrm{mol}$ of NADH per min.

The effect of $\mathrm{NaCl}$ on the recombinant BADHs was determined by incubating purified enzymes $(2 \mu \mathrm{g})$ in $50 \mathrm{mM}$ HEPES buffer ( $\mathrm{pH}$ 8.0), $0.5 \mathrm{mM} \mathrm{NAD}^{+}$and the indicated concentrations of $\mathrm{NaCl}$ for $5 \mathrm{~min}$ at $30^{\circ} \mathrm{C}$. After pre-incubation, $5 \mathrm{mM}$ betaine aldehyde was added and the activity was measured.

\section{Real-time PCR}

RNA isolation and real-time PCR were done as described previously (Mitsuya et al. 2005, Mitsuya et al. 2009). The primers used in this study are shown in Additional file 3. LcTubulin (accession number CN466136) was used as the internal control. The transcript level of target genes was normalized to that of LcTubulin (value $=1$ ).

\section{Assays of BADH activity in L. chinensis leaves}

The extraction of total soluble protein from the sixth leaf blades of L. chinensis plants and BADH assay by the fluorometric method were done as described previously (Arakawa et al. 1990).

\section{Protein gel-blot analyses of BADH and CMO proteins}

Total soluble protein was extracted from the sixth leaf blades of $L$. chinensis and barley plants as described previously (Burnet et al. 1995). For protein gel-blot analysis, proteins were electrophoresed on SDS-polyacrylamide gels, transferred to a polyvinylidene fluoride membrane and developed using an ECL Advance Western Blotting Detection Kit (GE healthcare biosciences, Piscataway, NJ, USA). Primary [rabbit anti-barley HvCMO peptides (Mitsuya et al. 2011) and anti-spinach BADH (Arakawa et al. 1992) IgGs] and secondary (peroxidase-conjugated donkey anti-rabbit IgG, GE Healthcare) antibodies were diluted in Can Get Signal solution (Toyobo, Osaka, Japan) at 1:1,000, 1:5,000 and 1:5,000, respectively. It was found that the anti-barley HvCMO peptides antibody can cross-react with CMO-like proteins in L. chinensis (Figures 3, 6). In addition, the partial sequence of CMO- like protein of L. chinensis (GenBank Accession No. ABV64740) is highly similar to that of barley HvCMO protein (93\% similarity) and the sequence of the two antigen peptides for anti-HvCMO peptides antibody is conserved between the two plant species.

\section{Determination of the concentration of GB and choline}

The concentration of GB was determined as reported previously (Jagendorf and Takabe 2001).

The extraction of choline from leaves was done according to Toyosawa and Nishimoto (1967). The choline was reacted with 1-naphthyl isocyanate to form a stable cationic aromatic urethane and measured by high performance liquid chromatography on a cation exchange column, followed by fluorescence detection as described in McEntyre et al. (2009).

\section{Immunofluorescent labeling of BADH and CMO proteins} Immunodetection of $\mathrm{BADH}$ and $\mathrm{CMO}$ proteins was performed as described previously (Mitsuya et al. 2011). Rabbit anti-spinach BADH (Arakawa et al. 1992) and Anti-HvCMO peptides (Mitsuya et al. 2011) IgGs were used for detection of $\mathrm{BADH}$ and $\mathrm{CMO}$, respectively. Fluorescein isothiocyanate-conjugated goat anti-rabbit IgG (Wako Pure Chemical Industries, Osaka, Japan) was used as a secondary antibody. The sections were observed using a confocal microscope (Carl Zeiss LSM 5 PASCAL). At least 3 samples were used for the analysis.

\section{Additional files}

Additional file 1: SDS-PAGE of recombinant LCBADH1 and LCBADH2. LCBADH1 and LCBADH2 were expressed as fusion proteins in Escherichia coli and purified as described in Methods. After enterokinase treatment, 10 $\mu \mathrm{g}$ protein was electrophoresed. SDS-PAGE samples were stained using Coomassie brilliant blue R-250 and the size of molecular mass standards are shown on the left in $\mathrm{kDa}$.

Additional file 2: Kinetic analysis of betaine aldehyde, $\omega$-aminoaldehyde and trimethylaminoaldehyde dehydrogenase activities of LCBADH1 and LCBADH2. Assays were performed under the standad conditions as described in Methods. Substrate-dependent activities were plotted against substrate concentration. Data represent the mean of three experiments $\pm S E$. AB-ald, 4-aminobutyraldehyde; AP-ald, 3-aminopropionaldehyde; TMAB-ald, 4-N-trimethylaminobutyraldehyde; TMAP-ald, 3-N-trimethylaminopropionaldehyde.

Additional file 3: Primers used in this study.

\section{Abbreviations}

AB-ald: 4-aminobutyraldehyde; AP-ald: 3-aminopropionaldehyde; BADH: Betaine aldehyde dehydrogenase; CMO: Choline monooxygenase; GABA: $\gamma$-aminobutyric acid; GB: Glycinebetaine; ORF: Open reading frame; PEAMT: Phosphoethanolamine N-methyltransferase; TMAB-ald: 4-Ntrimethylaminobutyrialdehyde; TMAP-ald: 3-N-trimethylaminopropionaldehyde.

Competing interests

The authors declare that they have no competing interests.

Authors' contributions

SM performed the expression analyses and biochemical work, analysed the data and drafted the manuscript. AT and KKO performed the enzymatic 
analyses and molecular biology work. TF analysed the data and helped in drafting the manuscript. $\Pi$ and $\Pi$ design the research work and helped in drafting the manuscript. All authors read and approved the final manuscript.

\section{Acknowledgements}

We thank Dr. Nobuhiro Mori (United Graduate School of Bioagricultural Sciences, Tottori University, Japan) for distributing TMAB-ald and TMAP-ald, Dr. Takanori Imai (Nagoya University, Japan) for advice on the measurement of choline concentration, Dr. Joyce Cartagena (Nagoya University, Japan) and Dr. Nicola S. Skoulding for critical reading of the manuscript. This work was supported by a Grant-in-Aid for scientific research (No. 20390177 and No. 22780011) from the Ministry of Education, Culture, Sports, Science and Technology of Japan (to T.T. and S.M., respectively).

\section{Author details}

${ }^{1}$ Graduate School of Bioagricultural Sciences, Nagoya University, Chikusa, Nagoya 464-8601, Japan. ${ }^{2}$ Research Institute, Meijo University, Tenpaku, Nagoya 464-8502, Japan.

\section{Received: 11 December 2014 Accepted: 23 April 2015 Published online: 30 April 2015}

\section{References}

Arakawa K, Katayama M, Takabe T (1990) Levels of betaine and betaine aldehyde dehydrogenase activity in the green leaves, and etiolated leaves and roots of barley. Plant Cell Physiol 31:797-803

Arakawa K, Mizuno K, Kishitani S, Takabe T (1992) Immunological studies of betaine aldehyde dehydrogenase in barley. Plant Cell Physiol 33:833-840

Arakawa K, Takabe T, Sugiyama T, Akazawa T (1987) Purification of betainealdehyde dehydrogenase from spinach leaves and preparation of its antibody. J Biochem 101:1485-1488

Arikit S, Yoshihashi T, Wanchana S, Uyen TT, Huong NTT, Wongpornchai S, Vanavichit A (2011) Deficiency in the amino aldehyde dehydrogenase encoded by GmAMADH2, the homologue of rice Os2AP, enhances 2-acetyl-1pyrroline biosynthesis in soybeans (Glycine max L.). Plant Biotech J 9:75-87

Awal HMA, Yoshida I, Doe M, Hirasawa E (1995) 3-aminopropionaldehyde dehydrogenase of millet shoots. Phytochemistry 40:393-395

Baker A, Sparkes IA (2005) Peroxisome protein import: some answers, more questions. Curr Opin Plant Biol 8:640-647

Binda C, Coda A, Angelini R, Federico R, Ascenzi P, Mattevi A (1998) Crystallization and preliminary X-ray analysis of polyamine oxidase from Zea mays L. Acta Crystallogr D 54:1429-1431

Bohnert HJ, Jensen RG (1996) Strategies for engineering water-stress tolerance in plants. Trends Biotechnol 14:89-97

Boyer JS (1982) Plant productivity and environment. Science 218:443-448

Bradbury LM, Gillies SA, Brushett D, Waters DLE, Henry RJ (2008) Inactivation of an aminoaldehyde dehydrogenase is responsible for fragrance in rice. Plant Mol Biol 68:439-449

Brouquisse R, Weigel P, Rhodes D, Yocum CF, Hanson AD (1989) Evidence for a ferredoxin-dependent choline monooxygenase from spinach chloroplast stroma. Plant Physiol 90:322-329

Burnet M, Lafontaine PJ, Hanson AD (1995) Assay, purification, and partial characterization of choline monooxygenase from spinach. Plant Physiol 108:581-588

Chen S, Yang Y, Shi W, Ji Q, He F, Zhang Z, Cheng Z, Liu X, Xu M (2008) Badh2, encoding betaine aldehyde dehydrogenase, inhibits the biosynthesis of 2-acetyl-1-pyrroline, a major component in rice fragrance. Plant Cell 20:1850-1861

Chen THH, Murata N (2011) Glycinebetaine protects plants against abiotic stress: mechanisms and biotechnological applications. Plant, Cell Environ 34:1-20

Chern MK, Pietruszko R (1995) Human aldehyde dehydrogenase E3 isozyme is a betaine aldehyde dehydrogenase. Biochem Biophys Res Commun 213:561-568

Díaz-Sánchez AG, González-Segura L, Mújica-Jiménez C, Rudiño-Piñera E, Montie C, Martínez-Castilla LP, Muñoz-Clares RA (2012) Amino acid residues critical for the specificity for betaine aldehyde of the plant ALDH10 isoenzyme involved in the synthesis of glycine betaine. Plant Physiol 158:1570-1582

Fitzgerald TL, Waters DLE, Henry RJ (2009) Betaine aldehyde dehydrogenase in plants. Plant Biol 11:119-130

Fujiwara T, Hori K, Ozaki K, Yokota Y, Mitsuya S, Ichiyanagi T, Hattori T, Takabe T (2008) Enzymatic characterization of peroxisomal and cytosolic betaine aldehyde dehydrogenases in barley. Physiol Plant 134:22-30
Fujiwara T, Mitsuya S, Miyake H, Hattori T, Takabe T (2010) Characterization of a novel glycinebetaine/proline transporter gene expressed in the mestome sheath and lateral root cap cells in barley. Planta 232:133-143

Grattan SR, Grieve CM (1985) Betaine status in wheat in relation to nitrogen stress and to transient salinity stress. Plant Soil 85:3-9

Hassan M, Morimoto S, Murakami H, Ichiyanagi T, Mori N (2007) Purification and characterization of 4-N-trimethylamino-1-butanol dehydrogenase of Pseudomonas sp. 13CM. Biosci, Biotechnol, Biochem 71:1439-1446

Hibino T, Meng Y, Kawamitsu Y, Uehara N, Matsuda N, Tanaka Y, Ishikawa H, Baba S, Takabe T, Wada K, Ishii T, Takabe T (2001) Molecular cloning and functional characterization of two kinds of betaine-aldehyde dehydrogenase in betaineaccumulating mangrove Avicennia marina (Forsk.) Vierh. Plant Mol Biol 45:353-363

Inada M, Ueda A, Shi W, Takabe T (2005) A stress-inducible plasma membrane protein 3 (ACPMP3) in a monocotyledonous halophyte, Aneurolepidium chinense, regulates cellular $\mathrm{Na}^{+}$and $\mathrm{K}^{+}$accumulation under salt stress. Planta 220:395-402

Incharoensakdi A, Matsuda N, Hibino T, Meng YL, Ishikawa H, Hara A, Funaguma T, Takabe T, Takabe T (2000) Overproduction of spinach betaine aldehyde dehydrogenase in Escherichia coli. Structural and functional properties of wild-type, mutants and E. coli enzymes. Eur J Biochem 267:7015-7023

Ishitani M, Arakawa K, Mizuno K, Kishitani S, Takabe T (1993) Betaine aldehyde dehydrogenase in the Gramineae: levels in leaves of both betaineaccumulating and nonaccumulating cereal plants. Plant Cell Physiol 34:493-495

Ishitani M, Nakamura T, Han SY, Takabe T (1995) Expression of the betaine aldehyde dehydrogenase gene in barley in response to osmotic stress and abscisic acid. Plant Mol Biol 27:307-315

Jagendorf AT, Takabe T (2001) Inducers of glycinebetaine synthesis in barley. Plant Physiol 127:1827-1835

Kawanabe S, Nan Y, Oshida T, Kou Z, Konno M, Matsumoto S (1994) Vegetation and soil of alkalined meadow steppe in Wulanaodu region, Inner Mongolia Mainland China. 1. comparison between meadow and pasture. Grassl Sci 40:294-300

Kawanabe S, Oshida T, Nan Y, Kou Z, Jiang J, Wei J, Kai T (1996) Vegetation and soil of alkalined meadow steppe in Wulanaodu region, Inner Mongolia, Mainland China. 3. comparison of soil alkalinity in habitats of two ecotypes of Aneurolepidium chinense. Grassl Sci 41:325-328

Kinnersley AM, Turano FJ (2000) Gamma aminobutyric acid (GABA) and plant responses to stress. Crit Rev Plant Sci 19:479-509

Larkin MA, Blackshields G, Brown NP, Chenna R, McGettigan PA, McWilliam H, Valentin F, Wallace IM, Wilm A, Lopez R, Thompson JD, Gibson TJ, Higgins DG (2007) Clustal W and Clustal X version 2.0. Bioinformatics 23:2947-2948

Livingstone JR, Maruo T, Yoshida I, Tarui Y, Hirooka K, Yamamoto Y, Tsutui N, Hirasawa E (2003) Purification and properties of betaine aldehyde dehydrogenase from Avena sativa. J Plant Res 116:133-140

McCue KF, Hanson AD (1992) Salt-inducible betaine aldehyde dehydrogenase from sugar beet: cDNA cloning and expression. Plant Mol Biol 18:1-11

McEntyre CJ, Slow S, Lever M (2009) Measurement of plasma free choline by high performance liquid chromatography with fluorescence detection following derivatization with 1-naphthyl isocyanate. Anal Chim Acta 644:90-94

McNeil SD, Rhodes D, Russell BL, Nuccio ML, Shachar-Hill Y, Hanson AD (2000) Metabolic modeling identifies key constraints on an engineered glycine betaine synthesis pathway in tobacco. Plant Physiol 124:153-162

Mitsuya S, Kozaki K, Takabe T (2013) Tissue localization of the glycine betaine biosynthetic enzymes in barley leaves. Plant Prod Sci 16:117-122

Mitsuya S, Kuwahara J, Ozaki K, Saeki E, Fujiwara T, Takabe T (2011) Isolation and characterization of a novel peroxisomal choline monooxygenase in barley. Planta 234:1215-1226

Mitsuya S, Taniguchi M, Miyake H, Takabe T (2005) Disruption of RCI2A leads to over-accumulation of $\mathrm{Na}^{+}$and increased salt sensitivity in Arabidopsis thaliana plants. Planta 222:1001-1009

Mitsuya S, Yokota Y, Fujiwara T, Mori N, Takabe T (2009) OsBADH1 is possibly involved in acetaldehyde oxidation in rice plant peroxisomes. FEBS Lett 583:3625-3629

Mohanty A, Kathuria H, Ferjani A, Sakamoto A, Mohanty P, Murata N, Tyagi AK (2002) Transgenics of an elite indica rice variety Pusa Basmati 1 harbouring the codA gene are highly tolerant to salt stress. Theor Appl Genet 106:51-57

Nakamura T, Yokota S, Muramoto Y, Tsutsui K, Oguri Y, Fukui K, Takabe T (1997) Expression of a betaine aldehyde dehydrogenase gene in rice, a 
glycinebetaine nonaccumulator, and possible localization of its protein in peroxisomes. Plant J 11:1115-1120

Nakamura T, Nomura M, Mori H, Jagendorf AT, Ueda A, Takabe T (2001) An isozyme of betaine aldehyde dehydrogenase in barley. Plant Cell Physiol 42:1088-1092

Nomura M, Hibino T, Takabe T, Sugiyama T, Yokota A, Miyake H, Takabe T (1998) Transgenically produced glycinebetaine protects ribulose 1,5-bisphosphate carboxylase/oxygenase from inactivation in Synechococcus sp. PCC7942 under salt stress. Plant Cell Physiol 39:425-432

Nomura M, Ishitani M, Takabe T, Rai AK, Takabe T (1995) Synechococcus sp. PCC7942 transformed with Escherichia coli Bet genes produces glycine betaine from choline and acquires resistance to salt stress. Plant Physiol 107:703-708

Nuccio ML, Russell BL, Nolte KD, Rathinasabapathi B, Gage DA, Hanson AD (1998) The endogenous choline supply limits glycine betaine synthesis in transgenic tobacco expressing choline monooxygenase. Plant J 16:487-496

Ochiai K, Matoh T (2001) Mechanism of salt tolerance in the grass species, Anneurolepidium chinense : I. growth response to salinity and osmotic adjustment. Soil Sci Plant Nutr 47:579-585

Oishi H, Ebina M (2005) Isolation of CDNA and enzymatic properties of betaine aldehyde dehydrogenase from Zoysia tenuifolia. J Plant Physiol 162:1077-1086

Papageorgiou GC, Murata N (1995) The unusually strong stabilizing effects of glycine betaine on the structure and function of the oxygen-evolving Photosystem II complex. Photosynth Res 44:243-252

Rathinasabapathi B, Burnet M, Russell BL, Gage DA, Liao PC, Nye GJ, Scott P, Golbeck JH, Hanson AD (1997) Choline monooxygenase, an unusual iron-sulfur enzyme catalyzing the first step of glycine betaine synthesis in plants: prosthetic group characterization and CDNA cloning. Proc Natl Acad Sci U S A 94:3454-3458

Rathinasabapathi B, McCue KF, Gage DA, Hanson AD (1994) Metabolic engineering of glycine betaine synthesis: plant betaine aldehyde dehydrogenases lacking typical transit peptides are targeted to tobacco chloroplasts where they confer betaine aldehyde resistance. Planta 193:155-162

Rees WA, Yager TD, Korte J, Von Hippel PH (1993) Betaine can eliminate the base pair composition dependence of DNA melting. Biochemistry 32:137-144

Renault H, Roussel V, El Amrani A, Arzel M, Renault D, Bouchereau A, Deleu C (2010) The Arabidopsis pop2-1 mutant reveals the involvement of GABA transaminase in salt stress tolerance. BMC Plant Biol 10:20

Rhodes D, Hanson AD (1993) Quaternary ammonium and tertiary sulfonium compounds in higher plants. Annu Rev Plant Physiol Plant Mol Biol 44:357-384

Sakamoto A, Murata A, Murata N (1998) Metabolic engineering of rice leading to biosynthesis of glycinebetaine and tolerance to salt and cold. Plant Mol Biol 38:1011-1019

Saneoka H, Nagasaka C, Hahn DT, Yang WJ, Premachandra GS, Joly RJ, Rhodes D (1995) Salt tolerance of glycinebetaine-deficient and glycinebetaine-containing maize lines. Plant Physiol 107:631-638

Su J, Hirji R, Zhang L, He C, Selvaraj G, Wu R (2006) Evaluation of the stressinducible production of choline oxidase in transgenic rice as a strategy for producing the stress-protectant glycine betaine. J Exp Bot 57:1129-1135

Takabe T, Hayashi Y, Tanaka A, Takabe T, Kishitani S (1998) Evaluation of glycinebetaine accumulation for stress tolerance in transgenic rice plants. In: Proceedings of International Workshop on Breeding and Biotechnology for Environmental Stress in Rice. Hokkaido Agricultural Experiment Station, Sapporo, pp 63-68

Tamura K, Stecher G, Peterson D, Filipski A, Kumar S (2013) MEGA6: molecular evolutionary genetics analysis version 6.0. Mol Biol Evol 30:2725-2729

Toyosawa I, Nishimoto U (1967) Systematic determination of various forms of choline in plants. Agr Biol Chem 31:275-283

Trossat C, Rathinasabapathi B, Weretilnyk EA, Shen TL, Huang ZH, Gage DA, Hanson AD (1998) Salinity promotes accumulation of 3dimethylsulfoniopropionate and its precursor S-methylmethionine in chloroplasts. Plant Physiol 116:165-171

Vaz FM, Wanders RJA (2002) Carnitine biosynthesis in mammals. Biochem J 361:417-429

Weigel P, Lerma C, Hanson AD (1988) Choline oxidation by intact spinach chloroplasts. Plant Physiol 86:54-60

Weretilnyk EA, Hanson AD (1990) Molecular cloning of a plant betaine-aldehyde dehydrogenase, an enzyme implicated in adaptation to salinity and drought. Proc Natl Acad Sci U S A 87:2745-2749
Wood AJ, Saneoka H, Rhodes D, Joly RJ, Goldsbrough PB (1996) Betaine aldehyde dehydrogenase in sorghum: molecular cloning and expression of two related genes. Plant Physiol 110:1301-1308

Xiao G, Zhang GY, Liu FH, Chen SY (1995) The study of the BADH gene in Atriplex hortensis. Chin Sci Bull 40:741-745

Yang WJ, Nadolskaorczyk A, Wood KV, Hahn DT, Rich PJ, Wood AJ, Saneoka H, Premachandra GS, Bonham CC, Rhodes JC, Joly RJ, Samaras Y, Goldsbrough PB, Rhodes D (1995) Near-isogenic lines of maize differing for glycinebetaine. Plant Physiol 107:621-630

\section{Submit your manuscript to a SpringerOpen ${ }^{\odot}$ journal and benefit from:}

- Convenient online submission

- Rigorous peer review

- Immediate publication on acceptance

- Open access: articles freely available online

- High visibility within the field

- Retaining the copyright to your article

Submit your next manuscript at $\gg$ springeropen.com 